\title{
Eliminating Faults in Fuel System of a Certain Type of Aircraft
}

\author{
Zhenwei Chen \\ (AVIC Shenyang Aircraft Corporation, Shenyang, 110850)
}

\begin{abstract}
This paper introduces in detail steps as how to analyze and eliminate the abnormal dangerous failure: fuel injection of a certain aircraft' fuel supercharging system by safe and quick means when out-field experimental equipment is limited so as to break a new path to eliminate faults of the out field.
\end{abstract}

Keywords- fuel system, fuel injection, catch fire

\section{INTRODUCTION}

A type aircraft in aircraft pressure refueling and engine drive Shi, respectively found from aircraft in fuel system fuselage tank security valve at, and fuel system fuselage tank booster speed pressure mouth at, and fuel system fuselage tank booster $\mathrm{u}$ shaped tube water mouth at large spray oil, if fault not excluded, on will serious endanger aircraft security, a on had occurred had for fuel system spray oil disposal improper, making serious accident of being burned.

\section{DeVelopment of Programs to Eliminate FAULTS IN FUEL SYSTEM OF AIRCRAFTS}

As the aircraft implements its missions in the outfield and there is no necessary experimental equipment for the fuel system experiment at the troubleshooting field, which poses great difficulties to analyzing the problem as well as insecure factors to handling the problem as quickly as possible because once the technical scheme is not correct or the measures to handle the problem is not adequate, it is easy to cause fire or even burn the aircraft at the site, the damage of which cannot be compensated. Therefore, the key problem is to come up with secure and reliable schemes to eliminate the problem as soon as possible.

Analyzes the fuselage after the oil parts after and possible hazards, field personnel consultation, under maximum security measures are taken, it is necessary to drive for recurrence of symptoms, or the fault could not be ruled out immediately, are as follows: (1) clean the machine before driving product oil, particularly the engine compartment and the product oil. (2) increased fire Member, and alert member staff, and makes they in height alert state; (3) let test member by that set of test program drive: first up moving right sent, and long time in slow state blow except product oil, in found no leak oil, continues to push throttle to $\mathrm{N} 1=70 \%-80 \%$, after received throttle to slow, then to also method disposal left sent, if found also no leak oil, double sent continues to increased throttle. (4) inspection personnel carefully observed and recorded before and after commissioning the tank level data.

\section{RECURRENCE OF FUEL INJECTION FAULTS IN THE}

\section{FUEL SYSTEM}

Ground personnel safety first fuselage tank lid open door living, safety valve removed, release pressurized fuel pipeline, and the top front of the front fuselage airplane from high to low, so that pressurized fuel pipeline when exhausted as far as possible, the aircraft parked after 10 minutes, when the aircraft U-shaped fuel booster, snorkel drainage port does not Mao, restored the plane and after wiping up body parts of splashing residual fuel oil, in order to prevent test fire.

In order to further determine the fault, decided to let Symptom test reproducibility, test driver before starting the right engine, maintained under idling conditions, and found that U-shaped fuel booster snorkel drainage port has more than a small amount of oil coming out, this phenomenon disappears in 1 minute after the estimated remaining oil blowing, we inform test driver pushes the throttle $\mathrm{N} 1=70 \%-80 \%, 1$ minute oil drain port is still not out, the right to send and receive notification test drivers throttle at idle, start left engine, left and launched a successful move after drainage port has no oil smoke, decided to test driver pushes the accelerator twin $\mathrm{N} 1=$ $70 \%-80 \%$, and found 52 boxes in aircraft fuel system safety valve at the tank body, the fuel system pressure fuselage tank pressurization speed mouth, pressurized fuselage tank fuel system U-shaped tube drainage mouth a lot of fuel injection, we immediately ordered the test driver to stop.

After stopping, the crew opened immediately deflates the wing fuel tank cap and remove the fuselage tank safety valve discharge of oil, the oil spray to stop. Test driver test group consumed reflect the full lamp is not lit, inspectors observed the oil tank through the data and found that the body of each oil tank data properly and did not change much, the wing fuel tank oil drop, no fuselage fuel tank oil Variety. This suggests that the phenomenon of the wing fuel tanks and the fuel injection fuel tanks boost the value of size (engine boost the value of the size of the state of the left and right) related. 


\section{ANALYSIS AND ELIMINATION OF FAULTS}

Through this, a preliminary analysis: the aircraft fuel system fuselage fuel tank safety valve in 52 box fuselage fuel tank, fuel system pressure port fuselage fuel tank, fuel system pressure u-tube water outlet a lot of oil, directly because the aircraft pressurization in the series in a lot of high pressure oil line.

Through the study of principle aircraft fuel systems, our preliminary view: normal aircraft fuel system oil control aircraft pressurized pipeline into the source of a lot of high pressure oil is the fuel in the wing tanks.

So, aircraft fuel tanks in the wings are how the string into the aircraft fuel pressurization line as well? By analyzing the fuel system principle, we can see that: Under normal circumstances, when the wing fuel tank of oil (the main group consumed $80 \mathrm{~kg}$ fuel tank, the float valve so that the 1st job), about the wing fuel solenoid valve in the closed position, plus fuel oil manifold $\Phi 62$ electric switch is in the open position, the Canadian oil explorer film shutter in the open position, the fuel inside the wing fuel tanks at $0.098 \pm 0.0029 \mathrm{MPa}$ boost pressure into the tank in the fuselage consumption group, and by signal control over oil; wing fuel tank vent valve is closed at the main supply pump, the same time as the Three float valve (not started) in relief and opened the wing tank pressurization valve, so that the wing tanks by direct vent pipe pressure pipe (rear of the plane, near the 50 boxes) is connected to the fuselage tank, so that the wing tank supercharging pressure becomes consistent with the fuselage tank (both $0.0206-0.00225 \mathrm{MPa}$ ) leaving no oil wing tank .

Under fault conditions, the wing fuel tanks in the fuel can enter the body through the following three forms in the tank pressurized pipeline:

(1) When the check valve pressure fuel line and add oil manifold connected to shut lax fuel inside the wing fuel tanks at $0.098 \pm 0.0029 \mathrm{MPa}$ boost pressure into the fuel tank in the fuselage of each group, and each group by the full oil tank float valve control (when filled with oil, control over oil control valve closed), referred to as "a failure mode";

(2) When refueling wing refueling pipeline electromagnetic valve closed lax, fuel pressure check valves loose relationship with the Canadian oil pipeline manifold connected to the fuel inside the wing fuel tanks at $0.098 \pm 0.0029 \mathrm{MPa}$ supercharging pressure, enter wing groups in the tank, and after the wing tanks pressurized tube group, wing tank pressure relief valve, wing and fuselage fuel tank pressurization valve into the tank through the trachea (rear of the plane, close to 50 frames), referred to "failure Mode II";

(3) Wing tank check valve pipeline strictly off the road, the same generation as "Failure Mode II" phenomenon, referred to as "failure mode three."

Compared this three species fault mode: "fault mode a" produced of conditions has "one-way valve shut not strict" and the "full oil control valve runaway" this two a, this situation fundamental impossible, because as long as pressure refueling Shi full oil control good, fuel on not into fuselage tank booster ventilation pipeline in the; and "fault mode II" and "fault mode three" phenomenon mode is a. "Failure mode" in the wing fuel tanks of oil pipeline road check valve plate check valve, prone to failure, and failure, breakdown cover is required to replace the faulty parts, difficult to exclude, this failure mode, should be placed in the last possible consideration. In this way, we should first consider the "failure mode II".

"Failure mode II", the wings left wing refueling boom the way solenoid valve has one or two doesn't stay closed, will cause the above symptoms.

How to troubleshoot fuel solenoid valve the wing good or bad? Because the wing fuel solenoid valve disassembly and Assembly workload particularly large and difficult, so we have to lock the wing fuel solenoid valve failure, can only proceed to the next step dismantle the wing fuel solenoid valve working.

Through the fuel system principle we can analyze that, if the fuel pressure control box plus oil switch to "oil" position, the left and right wing fuel tanks and unplug power, plus three auxiliary fuel tanks as fuel tanks are oil valve there is oil in the open position, if the fuel tank cap is opened, the engine driving: fuselage tank pressure tank pressure is consistent with the wing, the wing of the left and right wings of the bad fuel solenoid valve will be closed due to the lax side wing fuel tank, lower input potential fuselage fuel tank and the flow resistance in the smaller side of the wing fuel tanks (each wing fuel tank add oil manifold in both oil filter, oil filter has a flow resistance ). Ground again drive the process described above to drive discovery: Right wing fuel tanks oil rises, the fuselage fuel tank outward string of oil, which shows on the right wing fuel tank electromagnetic valve or check valve failure. Taken together, it should remove the fuel solenoid valve on the right wing.

After refueling solenoid valve by removing the right side of the wing, refueling at its entrance test and found to leak, not sealed, taking into account the RDK-29 is a solenoid valve, pressure refueling is only just opened, so the right side of the machine refueling wing electromagnetic valve for the cause of the malfunction.

Replacement off the side of the defective unit, re-pressure fuel, refueling was normal explanation left wing refueling check valve and solenoid valve non-faulty parts, so parts can be locked only one fault: Right wing fuel solenoid valve.

Ground engine driving again, and "slow", "largest", "Afterburner" States push throttle test fuel system works, indicating fault can be fully ruled out.

Come by measuring the direct cause of the defective unit on the right wing inside the solenoid valve circuit parameters, indicators of normal that failure of its members are catching cause mechanical failure, which leads to mechanical binding is due when the aircraft as the aircraft transitions emergency brake system brake valve leak causing the aircraft wheel brakes about 
coasting puncture dead, long airplane wing root cause jitter, which causes the right side of the wing fuel solenoid valve mechanical binding and strictly off the fuel inside the wing fuel tanks at $0.098 \pm$ By supercharging pressure $0.0029 \mathrm{MPa}$ of each group enter the wing tank, and after the wing tanks pressurized tube group, wing tank pressure relief valve, wing and fuselage fuel tank pressurization valve into the tank through the trachea, because there were a lot of aircraft attitude angle (high to low), so the fuel tank vent tube quickly into the body of the U-shaped ventilation tube, causing the aircraft fuel system in the fuselage frame 52 safety valve at the tank, the fuel system body speed boost pressure tank mouth, pressurized fuselage tank fuel system U-shaped tube drainage mouth Symptom lot of fuel injection. This fault system and other parts of the aircraft are not necessarily linked.

If similar failures in the future, how to judge is on the left wing refueling solenoid valve, or right wing fuel solenoid valve malfunction? Aircraft fuel system according to the knowledge of fluid mechanics principles and able to tell there are two simple methods.

Method One: Oil fuel tank judgment method, first the fuselage fuel tank to fill and write down the oil scale, the wing fuel tank provision added to the oil scale, check the oil level scale fuselage fuel tank again test as described above, the left and right wing fuel tank oil face the scale, if the oil does not drop the fuselage fuel tank, a side wing fuel tanks oil rises, the other side of the wing fuel tanks oil falls, with oil rising to the side of the wing fuel tanks refueling wing interlinked pipeline electromagnetic strictly off valve, solenoid valve because the fluid fuel into the wing tank closest to the minimum flow resistance from strictly off wing.

Method Two: Left and right wheel compartment wing tank breather into the oil law judge, leading off from the wing tanks wing tank vent valve wing tank vent line (left and right wheels cabin fittings to connect the upper frame
33), if a side round the cabin from the wing tank ventilation valve leading to the wing tank fuel pressurizing conduit into the kerosene, indicating that the side wing fuel solenoid valve closed lax, the side of the wing fuel tanks of fuel into the wing tank to the side, and then from the wing tanks to enter the wing tank vent valve leading ventilation pipe. Because the wing fuel solenoid valve in the wing and fuselage of the foreskin, dismantling more difficult and time-consuming, power also need to check the foreskin removable cover, so the above method is the easiest, most possible intuitive way.

\section{CONCLUSIONS}

After the above measures to eliminate troubles, failures of the aircraft fuel system have been ruled out, and through communicating with pilots, their concerns have been eliminated, safeguarding the flight tasks of important aircraft types.

\section{REFERENCES}

[1] "Aircraft Specifications" [M] Shenyang Aircraft Design Institute of the Aviation Industry

[2] "Fluid Mechanics" [M] Tsinghua University Press

\section{INTRODUCTION TO THE AUTHOR:}

Chen Zhenwei (1975.09.01-), male, from Xifeng, Liaoning, intermediate engineer, Military Product Sales Department of AVIC Shenyang Aircraft Corporation, mainly engaged in researching aircraft system debugging and test while hosting and completing various national key aircraft debugging tasks and taking part in debugging fuel system of domestic military aircrafts. Correspondence Address: No. 15 sub-branch of No.328 mailing box, Shenyang Aircraft Corporation, No.1 Lingbei Street, Shenyang, Liaoning. Zip Code: 110850 E-mail:1693706590@qq.com, Phone: 13889146372. 